\title{
COOPERAÇÃO JUDICIÁRIA EM MATÉRIA CIVIL NA UNIÃO EUROPEIA E COBRANÇA DE CRÉDITOS. IMPORTÂNCIA DA TRAMITAÇÃO PREJUDICIAL URGENTE
}

\section{COOPERACIÓN JUUDICIAL EN MATERIA CIVIL EN LA UNIÓN EUROPEA Y COBRO DE CRÉDITOS. IMPORTANCIA DE LA TRAMITACIÓN PREJUDICIAL URGENTE}

Joana Covelo de Abreu*

Resumo: Na União Europeia houve a preocupação de desenvolver um Espaço de Liberdade, Segurança e Justiça onde foram criados mecanismos de adensamento de uma cooperação judiciária em matéria civil. Sobretudo desde a crise económica aí vivenciada, criou-se uma preocupação com a cobranca de créditos, onde foram adotados meios processuais europeus (procedimento de injunção, ações de pequeno montante e arresto de contas bancárias), de carácter célere e simplificado, a fim de evitar gastos excessivos e potenciar a observância das liberdades fundamentais e o bom funcionamento do Mercado Interno. As preocupações mantiveram-se e o ano de 2017 surge como decisivo já que foram realizadas algumas alterações ao procedimento de injunção e às ações de pequeno montante (aplicáveis a partir de julho de 2017) e o regime de arresto é aplicável desde janeiro de 2017. Como cabe aos tribunais nacionais tramitarem a cobrança de créditos à luz destes instrumentos, o reenvio prejudicial assume particular relevância a fim de debelar dúvidas interpretativas / de validade que se lhes coloquem. Assim, os tribunais nacionais têm de desenvolver a conviç̧ão de que dispõem da faculdade para requerer que tais reenvios observem a tramitação prejudicial urgente na medida em que a mesma já se encontra disponível há vários anos e, no entanto, nunca foi requerida e / ou decretada para este tipo de processos, apesar de material e casuisticamente, a cobrança de créditos a ela ser subsumível e poder gozar desta tramitação mais expedita. Só assim se promove uma real integração

* Universidade do Minho, Portugal.

E-mail: jabreu@direito.uminho.pt

Recibido: 20/06/2017. Aceptado: 07/08/2017. 
judiciária em matéria civil, para a qual a União já começou a dar os primeiros - mas decisivos! - passos.

Resumen: En la Unión Europea se planteó la preocupación de desarrollar un Espacio de Libertad, seguridad y justicia, en el que se crearon mecanismos para el fortalecimiento de una cooperación judicial en materia civil. Sobre todo, desde la crisis económica allí vivida, se creó una preocupación por el cobro de créditos, donde se adoptaron medios procesales europeos (proceso monitorio europeo, proceso europeo de escasa cuantía y orden europea de retención de cuentas), de carácter rápido y simplificado, a fin de evitar gastos excesivos y potenciar el cumplimiento de las libertades fundamentales y el buen funcionamiento del Mercado Interior. Las preocupaciones se mantuvieron y el año de 2017 surge como decisivo ya que se realizaron algunas modificaciones al proceso monitorio europeo y al proceso europeo de escasa cuantía (aplicables a partir de julio de 2017) y el régimen de orden europea de retención de cuentas es aplicable desde enero de 2017. Como corresponde a los tribunales nacionales tramitar el cobro de créditos a la luz de estos instrumentos, la remisión prejudicial reviste particular relevancia para resolver las dudas interpretativas / de validez que se les planteen. Así, los tribunales nacionales tienen que desarrollar la convicción de que disponen de la facultad para solicitar que tales recursos observen la tramitación prejudicial urgente en la medida en que la misma ya se encuentra disponible desde hace varios años $y$, sin embargo, nunca fue requerida y / o decretada para este tipo de procesos, a pesar de material y casuísticamente, el cobro de créditos a ella ser subsumible y poder gozar de esta tramitación más expedita. ;Sólo así se promueve una verdadera integración judicial en materia civil, para la que la Unión ya ha comenzado a dar los primeros - pero decisivos!, pasos.

Palavras-chave: Procedimento europeu de injunção, Ações de pequeno montante, Arresto de contas, Cooperação judiciária em matéria civil, Tramitação prejudicial urgente

Palabras clave: Proceso monitorio europeo, Proceso europeo de escasa cuantía, Orden europea de retención de cuentas, Cooperación judicial en materia civil, Procedimiento prejudicial de urgencia

\section{INTRODUÇÃO}

O Tratado de Lisboa, desde a sua aprovação, configurou-se como um ponto marcante na história da integração europeia na medida em que acarretou a abolição das Comunidades ${ }^{1}$, o que determinou que "a

\footnotetext{
$\overline{1 \text { A década de } 50}$ do século XX ficou marcada pela criação de três Comunidades: a Comunidade Europeia do Carvão e do Aço (CECA), a Comunidade Europeia e a Comunidade Europeia da Energia Atómica (EUROTOM). Assim, a CECA extinguiu-se porque o Tratado de Paris caducou em 2002; a Comunidade Europeia foi sucedida pela União Europeia com a entrada em vigor do Tratado de Lisboa; por último, apesar de a EUROTOM se manter,
} 
palavra "comunitário" se torn[asse], portanto, obsoleta"2.

No contexto da cooperação judiciária em matéria civil - e, especificamente, no que diz respeito à cobrança de créditos na União Europeia - cabe demonstrar que o Tratado de Lisboa também asseverou o desaparecimento dos pilares comunitários, "com especial ênfase para a determinação de uma competência alargada do Tribunal de Justiça da União Europeia (TJUE) a todas as matérias reguladas nos tratados"3.

Assim, das competências delineadas no seio da União Europeia, resulta do disposto no artigo $4^{\circ}, \mathrm{n}^{\circ} 2, \mathrm{j}$ ) do Tratado sobre o Funcionamento da União Europeia (TFUE) que a União Europeia e os Estados-Membros exercem competências partilhadas no domínio do Espaço de Liberdade, Segurança e Justiça. Tal significa que "tanto a União como os EstadosMembro gozam de iniciativa legiferante" .

Ademais, numa União Europeia marcada pelas liberdades económicas de circulação e pelo estabelecimento de um mercado interno, houve a necessidade de criar e de sedimentar um espaço onde se acautelassem sensibilidades demonstradas por quem efetivamente exercia ativamente tais liberdades. Surge, assim, o Espaço de Liberdade, Segurança e Justiça, tal como o mesmo se encontra desenhado nos termos dos artigos $67^{\circ}$ e seguintes do TFUE. Na realidade, determina o artigo $67^{\circ}, \mathrm{n}^{\circ} 1$ que "[a] União Europeia constitui um espaço de liberdade, segurança e justiça, no respeito dos direitos fundamentais e dos diferentes sistemas e tradições jurídicos dos Estados-Membros". Sob o chapéu deste Espaço desenvolve-se a cooperação judiciária em matéria civil, conforme se deriva do texto do artigo $67^{\circ}, \mathrm{n}^{\circ} 4$ do TFUE: “a União facilita o acesso à justiça, nomeadamente através do princípio do reconhecimento mútuo das decisões judiciais e extrajudiciais em matéria civil".

A cooperação judiciária em matéria civil dá observância ao princípio do reconhecimento mútuo já que é este que "permite uma harmonização de lacunas e uma aproximação das legislações nacionais dos diversos Estados-Membros" ${ }^{\prime 2}$ sempre que estes não se vejam em

atento o Protocolo no 2 anexo ao Tratado de Lisboa, a realidade é que o seu objeto - centrado especificamente na energia atómica - não se subsume à vocação da atual União Europeia. Para maiores desenvolvimentos, DUARTE, Maria Luísa. Estudos sobre o Tratado de Lisboa. Coimbra: Almedina, 2010, p. 27-28.

2 BIAVATI, Paolo. "L'avenir du droit judiciaire privé d'origine européenne. Del'harmonisation des règles à l'harmonisation des effets”. RTDeur - Revue trimestrielle de droit européen. 2010, vol 46, n 3, p. 564 (tradução livre).

3 ABREU, Joana Covelo de. "O procedimento europeu de injunção de pagamento: solução simplificada de cobrança de créditos transfronteiriços?”. Em: ROCHA, Joaquim Freitas da (Ed.). Anuário Publicista da Escola de Direito da Universidade do Minho (e-book) [online]. Braga: Departamento de Ciências Jurídicas Públicas, Escola de Direito da Universidade do Minho, 2014. tomo 2, p. 77 [consulta 09/06/2017]. Disponível em: <https://issuu.com/ eduminho/docs/final_anu__rio_2013_etica_e_direito>

4 Ibíd., p. 78.

5 Cfr. ABREU, Joana Covelo de. "A tutela jurisdicional efetiva no âmbito da cooperação 
condições de levar a cabo tal finalidade ${ }^{6}$. Ao reconhecimento mútuo há que agregar - sem possibilidade de dissociação - o princípio da confiança recíproca na medida em que não seria viável proclamar uma relação de mútuo reconhecimento, sobretudo num cenário que transcende, como veremos, a mera cooperação judiciária, "[s]em confiança"

$\mathrm{O}$ artigo $81^{\circ}$ do TFUE estabelece, no âmbito do direito originário, que é à União Europeia que cabe desenvolver uma cooperação judiciária em matéria civil, assente na observância do princípio do reconhecimento mútuo e que pode passar pela adoção de medidas de aproximação das disposições legislativas e regulamentares dos Estados-Membros. Assim, os instrumentos de cobrança transfronteiriça de créditos foram adotados pelo Parlamento Europeu e pelo Conselho, observando o procedimento legislativo ordinário ${ }^{8}$, a fim de promover um melhor acesso à justiça e a eliminação dos obstáculos à boa tramitação das ações cíveis (conforme resulta do disposto no artigo $81^{\circ}, \mathrm{n}^{\circ} 2$, e) e f) do TFUE).

Assim, este texto ganha particular relevância na medida em que todos os mecanismos de cobrança de créditos que iremos tratar foram objeto de aplicação no ano de 2017 - como iremos ver, foram promovidas algumas alterações de fundo ao funcionamento das ações de pequeno montante e ao procedimento europeu de injunção cuja aplicação plena ocorre em Julho de 2014; por sua vez, o regime de arresto de contas bancárias também apenas se passou a aplicar a partir de Janeiro de 2017.

Deste modo, antevê-se que muitas serão as dúvidas nomeadamente interpretativas - que se irão colocar aos tribunais que terão de implementar tais mecanismos processuais, as quais apenas poderão ser dirimidas através do salutar diálogo entre os tribunais nacionais (responsáveis por tramitar tais mecanismos de cobrança de créditos) e o Tribunal de Justiça, o órgão competente para se pronunciar sobre o sentido e / ou a validade do direito da União aplicável. Tal diálogo opera-se através do reenvio prejudicial, consagrado no artigo $267^{\circ}$ do TFUE.

Assim, começaremos por analisar brevemente os mecanismos de cobrança de créditos existentes no contexto da União para, em seguida,

\footnotetext{
judiciária em matéria civil e a jurisprudência do Tribunal de Justiça da União Europeia: a cláusula de ordem pública e a revelia absoluta como causas de recusa de reconhecimento e de execução de decisões no contexto da União" [online]. UNIO - EU Law Journal 2014, n 0. Braga: Centro de Estudos em Direito da União Europeia, 2014, p. 147-161, p. 150 [consulta 09/06/2017]. Disponível em: <http://www.unio.cedu.direito.uminho.pt/Uploads/UNIO\%20 PT/UNIO\%200\%20-\%20Joana\%20Abreu_pt.pdf>

6 NASCIMBENE, Bruno. "Le traite de Lisbonne et l'espace judiciaire européen : le principe de confiance réciproque et de reconnaissance mutuelle". Revue des Affaires Européennes - Law \& European Affairs, 2012, p. 787 (tradução livre).

7 Ibíd., p. 789 (tradução livre).

8 Para maiores desenvolvimentos, consultar artigo $294^{\circ}$ do TFUE. Afinal, o procedimento legislativo ordinário pressupõe que a iniciativa legislativa fica confiada à Comissão Europeia e que o ato legislativo será adotado, em conjunto e codecisão, pelo Parlamento Europeu e pelo Conselho, observando as próprias regras da maioria de cada uma destas instituições.
} 
apreender como o reenvio prejudicial funciona neste contexto e, bem assim, como se poderá requerer e ver deferida a sua tramitação urgente.

\section{A COBRANÇA DE CRÉDITOS NA UNIÃO EUROPEIA E A IMPORTÂNCIA DA TRAMITAÇÃO PREJUDICIAL URGENTE}

\subsection{A cobrança de créditos na União Europeia}

No seio do desenvolvimento de uma mais densa e aprofundada cooperação judiciária em matéria civil, a União Europeia desenvolveu três mecanismos no sentido de promover a viabilização de uma célere e eficaz cobrança de créditos não liquidados no contexto transfronteiriço que caracteriza a Europa, criando concretos e prementes benefícios para as empresas e particulares.

Assim, a União Europeia começou por adotar o Regulamento $\mathrm{n}^{\circ} 1896 / 2006^{9}$, que criou um procedimento europeu de injunção de pagamento - a sua génese associa este procedimento ao pragmatismo, à rapidez, à celeridade. No entanto, tal pode determinar que se perca a intervenção judicial strictu sensu, na medida em que, dependendo das informações prestadas pelos Estados-Membros, poderá caber a uma entidade parajudicial e / ou administrativa a competência para tramitar esta injunção europeia. A sua criação foi bastante aplaudida pelos agentes económicos na medida em que "os atrasos de pagamento representam uma das principais causas de falência que ameaçam a sobrevivência das empresas, em especial das pequenas e médias empresas, e provocam a perda de inúmeros postos de trabalho"10. Afinal, apesar de a maioria dos Estados-Membros se encontrar dotada de mecanismos de cobrança facilitada de créditos não liquidados, a realidade é que "a Europa era, nesse domínio, uma verdadeira Babel, marcada por fortes assimetrias ao nível dos requisitos formais e substantivos, prazos, autoridades competentes (desde logo «juiz» versus «funcionários» [...]) e encadeado de regras adjetivas"11. Assim, este mecanismo de injunção europeia de pagamento surge como "um processo-tipo, único, célere e suscetível de produzir resultados efetivos, potenciadores da economia e credibilizadores dos conceitos de Justiça Europeia e Espaço Judiciário Comum"12.

Este mecanismo produzirá integralmente os seus efeitos caso o devedor, citado para se opor à injunção, não o fizer, circunstância em que

9 PARLAMENTO EUROPEU E CONSELHO. Regulamento (CE) no 1896/2006, de 12 de dezembro de 2006, que cria um procedimento europeu de injunção de pagamento [consulta 09/06/2017]. Disponível em: <http://eur-lex.europa.eu/legal-content/PT/TXT/?qid=15017475 26470\&uri=CELEX:32006R1896>

10 Regulamento (CE) no 1896/2006, considerando 6.

11 MARINHO, Carlos M.G. de Melo. A cobrança de créditos na Europa. Os processos europeus de injunção e pequenas causas. Lisboa: Quid Juris, 2012, p. 19.

12 Ibíd., p. 20. 
o credor congrega, através da aposição de formula executória à injunção, um título executivo europeu que independe de qualquer medida de reconhecimento e / ou de declaração de executoriedade ${ }^{13}$, podendo o credor livremente executar o devedor no Estado-Membro onde lhe for mais favorável a obter o cumprimento. A injunção permite, ao credor, reclamar o pagamento de créditos que detém sobre outrem desde que se verifique 1) que existe uma dívida; 2) que esta se encontre pendente ${ }^{14}$; e 3) que não seja judicialmente controvertida ${ }^{15}$. Em regra, por força do artigo $2^{\circ}$ do Regulamento, este procedimento servirá para demandar o pagamento de créditos emergentes de contratos, excluindo-se da sua aplicação os créditos resultantes de factos ilícitos ${ }^{16}$. Serve ainda para cobrar créditos de natureza pecuniária, que se encontrem "apurados e totalmente determinados" e que possam ser "peticionados em termos presentes e não meramente futuros"17. Não se lhe impõe qualquer limite pecuniário.

Também no sentido de promover uma eficaz e célere cobrança de créditos, a União Europeia adotou o Regulamento no 861/2007 ${ }^{18}$, que estabeleceu um processo europeu para ações de pequeno montante e que comunga com o procedimento europeu de injunção no ensejo de dotar a União de um espaço onde vigore a livre circulação de decisões judiciais já que "[a] vontade de construir um espaço judiciário europeu levou [...] a que o legislador da União ultrapassasse a via da simples coordenação dos processos nacionais, procedendo a avanços na aplicação de processos [...] específicos, destinados a regular mais rápida e eficazmente os litígios transfronteiriços, como [...] o processo europeu para ações de pequeno montante" 19 . A ações de pequeno montante, como a designação faz antever, destinam-se a atuar no âmbito da litigância de "baixa densidade"20 já que se verificou que existe

13 Para maiores desenvolvimentos, ABREU, Joana Covelo de. "A tutela jurisdicional efetiva no âmbito da cooperação judiciária em matéria civil e a jurisprudência do Tribunal de Justiça da União Europeia: a cláusula de ordem pública e a revelia absoluta como causas de recusa de reconhecimento e de execução de decisões no contexto da União". Op. cit.

14 MARINHO, Carlos M. G. de Melo. Op. cit., p. 23.

15 Regulamento (CE) no 1896/2006, considerando 6.

16 Ressalte-se, no entanto, que é admissível a reclamação de créditos emergentes da compropriedade de bens, por força do disposto no artigo $2^{\circ}, n^{\circ} 2, d$ ), ii) do Regulamento. No entanto, o regime de demanda de créditos contratuais parece ter sido influenciado pelo sistema francês, que também prioriza, no seu procedimento interno de injunção, a cobrança de créditos de natureza contratual. Para maiores desenvolvimentos, MARINHO, Carlos M.G. de Melo. Op. cit., p. 23.

17 Ibíd., p. 24.

18 PARLAMENTO EUROPEU E CONSELHO. Regulamento (CE) $n^{\circ}$ 861/2007, de 11 de julho de 2007, que estabelece um processo europeu para ações de pequeno montante [consulta 09/06/2017). Disponível em: <http://eur-lex.europa.eu/legal-content/PT/TXT/?qid=15017476 71600\&uri=CELEX:32007R0861>

19 Conclusões do Advogado-Geral Yves Bot no processo Alder vs. Orlowska, de 20 de setembro de 2012, processo $\mathrm{n}^{\circ} \mathrm{C}-325 / 11$.

20 A expressão pertence a Carlos Marinho, para quem se remete. No entanto, a sua clara precisão terminológica, aliada a um sentido literário invejável, impele-nos a adotá-la. A propósito, MARINHO, Carlos M. G. de Melo. Op. cit., p. 95. 
um grande ratio de créditos não pagos cujo montante não excede os $10.000,00 €^{21}$. Assim, inicialmente estas tinham em vista obter a cobrança de créditos do montante de $2.000,00 €$, recentemente atualizado para um novo limiar de 5.000,00€. Ora, com o advento da crise económica que marcou a União Europeia e os seus destinos, a Comissão aventou, no seu Relatório de 8 de maio de 2013 sobre a "Cidadania da União", que as ações de pequeno montante iriam contribuir decisivamente para uma das novas finalidades imputadas à União: a promoção da recuperação económica e do crescimento sustentável ${ }^{22}$.

No entanto, neste contexto de crise, detetou-se que, sobretudo as ações de pequeno montante, mas também, ainda que circunstanciadamente, o procedimento europeu de injunção, eram mais morosos do que se pretendia, embora já tivessem decorrido alguns anos desde a sua entrada em vigor, razão pela qual foi adotado o Regulamento $n^{\circ} 2015 / 2421^{23}$ que "acarreta algumas alterações ao funcionamento quer das ações de pequeno montante, quer do procedimento europeu de injunção" ${ }^{24}$. Tais mutações aplicam-se a partir do dia 14 de julho de 2017 e vão no sentido de conferir maior operatividade aos mecanismos, tendo uma das principais alterações determinado que o montante do crédito capital ${ }^{25}$ objeto das ações de pequeno montante fosse aumentado

21 Para maiores desenvolvimentos, consultar COMISSÃO EUROPEIA. Proposta de Regulamento do Parlamento Europeu e do Conselho, que altera o Regulamento(CE) nº 861/2007, do Parlamento Europeu e do Conselho, de 11 de julho de 2007, que estabelece um processo europeu para ações de pequeno montante, e o Regulamento (CE) nº 1896/2006, do Parlamento Europeu e do Conselho, de 12 de dezembro de 2006, que cria um procedimento europeu de injunção de pagamento. Bruxelas: 19.11.2013, COM(2013) 794 final, 2013/0403(COD), p. 6 [consulta 10/06/2017]. Disponível em: <http://ec.europa.eu/transparency/regdoc/rep/1/2013/ PT/1-2013-794-PT-F1-1.Pdf $>$. No mesmo sentido, tendo em conta as considerações críticas por nós avançadas, ABREU, Joana Covelo de. "O impacto do Regulamento no 2015/2421 no funcionamento das ações de pequeno montante - compreensões quanto à justiça eletrónica europeia". Em: FONSECA, Isabel; FROUFE, Pedro Madeira; e ROCHA, Joaquim Freitas da (Ed.). Livro em Homenagem ao Professor Doutor Cândido Oliveira, Braga: 2017, no prelo, p. 5 (provisório).

22 COMISSÃO EUROPEIA. EU Citizenship Report 2013, EU citizens: your rights, your future. Bruxelas: 08.05.2013, $\operatorname{COM(2013)~} 269$ final, p. 15 [consulta 10/6/2017]. Disponível em: $<$ http://ec.europa.eu/justice/citizen/files/com_2013_269_en.pdf >

23 PARLAMENTO EUROPEU E CONSELHO. Regulamento (UE) no 2015/2421, de 16 de dezembro de 2015, que altera o Regulamento (CE) no 861/2007 que estabelece um processo europeu para ações de pequeno montante e o Regulamento (CE) no 1896/2006 que cria um procedimento europeu de injunção de pagamento [consulta 10/6/2017]. Disponível em:

<http://eur-lex.europa.eu/legal-content/PT/TXT/?qid=1501748132862\&uri=CELEX:3201 $5 \mathrm{R} 2421>$

24 ABREU, Joana Covelo de. "O impacto do Regulamento no 2015/2421 no funcionamento das ações de pequeno montante - compreensões quanto à justiça eletrónica europeia”. Op. cit., p. 3 (provisório).

25 Falamos em crédito capital na medida em que, para a definição do valor da ação, é tido como referencial o montante em dívida, dele se excluindo os juros, os custos e quaisquer outras despesas, conforme resulta do disposto no artigo $2 .^{\circ}, \mathrm{n}^{\circ} 1$ do Regulamento $\mathrm{n}^{\circ} 861 / 2007$. Assim, ainda que somados tais valores e encontrado um valor superior ao montante atualmente em vigor de 5.000,00€, se o montante inicial em dívida era inferior, então a matéria insere-se no âmbito de aplicação deste Regulamento. 
de $2.000,00 €$ para $5.000,00 €$.

No entanto, a cobrança de créditos saiu ainda mais reforçada com a adoção do Regulamento ${ }^{\circ} 655 / 2014^{26}$ que veio estabelecer um procedimento de decisão europeia de arresto de contas bancárias. Em conjunto com o procedimento de injunção e as ações de pequeno montante, "o arresto de contas bancárias tem em vista facilitar a cobrança rápida e eficaz de créditos não liquidados, assegurando, ao credor, que o património do devedor não é dissipado por este ou por outrem, a seu mando"27.

A par da injunção europeia e das ações de pequeno montante, este mecanismo de arresto "configura-se como um processo europeu uniforme que pode ser usado pelos litigantes como alternativo aos meios previstos no direito nacional - considerando 6 e artigo $1^{\circ}, \mathrm{n}^{\circ} 2$ do Regulamento"28.

No caso do arresto de contas bancárias, verificamos que o mesmo tem em vista facilitar a cobrança de créditos na medida em que "ter de usar diversos procedimentos nacionais acabava por ser complexo e dispendioso"29. Assim, e como a União ainda não se dotou de um processo executivo europeu, continuando a confiar nas soluções jurídico-processuais nacionais, houve a necessidade de assegurar que os bens, nomeadamente de carácter monetário, poderiam ficar salvaguardados através de um procedimento cautelar especificado / tipificado tendente a promover uma "apreensão judicial de bens com caráter provisório" que "emerge de um processo de natureza cautelar e que pode ser decretado previamente à propositura de um processo executivo (quer no âmbito de uma ação declarativa, quer antes da apresentação desta ação em juízo)" ${ }^{30}$. Parece-nos, assim, como já tivemos oportunidade de expor, que "o legislador da União pensou num mecanismo provisório que, aprioristicamente, poderá ser capaz de facilitar a cobrança transfronteiriça de créditos (que se lhe seguirá) e que visa não comprometer o equilíbrio hercúleo entre o direito à ação e os direitos de defesa" 31 .

26 PARLAMENTO EUROPEU E CONSELHO. Regulamento (UE) $n^{\circ}$ 655/2014, de 15 de maio de 2014, que estabelece um procedimento de decisão europeia de arresto de contas para facilitar a cobrança transfronteiriça de créditos em matéria civil e comercial [consulta 10/06/2017]. Disponível em: <http://eur-lex.europa.eu/legal-content/PT/TXT/?qid=1501748285202\&uri= CELEX:32014R0655>

27 ABREU, Joana Covelo de. "O Regulamento no 655/2014 que estabelece um procedimento de decisão europeia de arresto de contas: direitos à ação e de defesa em tensão reflexiva no contexto de uma integração judiciária em matéria civil - uma precoce antevisão". Em: SILVEIRA, Alessandra (Ed.). UNIO - e-book, Vol. I, Workshops CEDU 2016 [online]. Braga: Centro de Estudos em Direito da União Europeia, 2017, p. 253-276, p. 254 [consulta 19/06/2017]. Disponível em: <http://www.unio.cedu.direito.uminho.pt/Uploads/E-book\%20 -\%20Vol.\%201\%20-\%202016.pdf>

28 Ibíd., p. 255.

29 Ídem.

30 Ibíd., p. 258.

31 Ibíd., p. 259. 
Está, assim, criado o status quo que nos demanda esta reflexão na realidade, com a criação e sedimentação de meios mais eficazes de cobrança de créditos, há a necessidade de verificar como os mesmos serão aplicados a fim de não comprometer a uniformidade do direito da União. Na realidade, o direito da União Europeia é maioritariamente aplicado pelos tribunais nacionais - para os quais estes mecanismos também nos conduzem -, havendo a necessidade de assegurar que estes não comprometerão a efetividade do direito da União, quando atuam como tribunais funcionalmente europeus ou como "tribunais de direito comum da União Europeia"32.

Do que ficou explanado, verificamos que as soluções de cobrança de créditos passam pela adoção de atos normativos gerais e abstratos os Regulamentos - que são diretamente aplicáveis aos ordenamentos jurídicos dos diversos Estados-Membros. Mas a novidade destes atos legislativos europeus prende-se com o facto de criarem soluções jurídicoprocessuais europeias, em que grande parte do processado é regida única e exclusivamente pelos termos consignados nos Regulamentos respetivos. No entanto, há domínios em que os Regulamentos em questão confiam nas soluções processuais dos Estados-Membros, dando plena observância ao princípio geral da autonomia processual dos Estados-Membros que determina que lhes cabe criarem as vias recursórias adequadas a promover os direitos decorrentes da ordem jurídica europeia - cf., a propósito, artigo $19^{\circ}, \mathrm{n}^{\circ} 1,2^{\circ}$ parágrafo do TUE.

Por sua vez, as soluções atinentes às injunções europeias, às ações de pequeno montante e ao arresto de contas serão sempre aplicadas pelos tribunais nacionais, observando as regras de conflitos decorrentes da ordem jurídica europeia ${ }^{33}$, atuando como pontes de transição, verificando-se a existência de um sistema de normas em rede decorrentes de distintas fontes (a europeia e a nacional, através das devoluções pontuais realizadas para as soluções processuais do Estado-Membro do foro), que convivem no mesmo espaço e que determinam como os litígios irão tramitar. Neste contexto, demanda-se uma articulação entre o órgão jurisdicional nacional, atuando como agente europeu, e o Tribunal de Justiça, na qualidade de exclusivo intérprete do direito da União.

Cria-se, assim, a necessidade de averiguar as relações de interação reflexiva entre ordenamentos jurídicos distintos - o do Estado-Membro do foro e o da União Europeia - que se operará, de forma cabal, através

32 Para maiores desenvolvimentos, PIÇARRA, Nuno. "As incidências do direito da União Europeia sobre a organização e o exercício da função jurisdicional dos Estados-Membros". Revista da Faculdade de Direito da Universidade do Porto, 2010, vol 8, p. 212.

33 A propósito, é aplicável, à definição da competência dos tribunais dos Estados-Membros, o Regulamento (UE) no 1215/2012, do Parlamento Europeu e do Conselho, de 12 de dezembro de 2012, relativo à competência judiciária, ao reconhecimento e à execução de decisões em matéria civil e comercial [consulta 10/06/2017]. Disponível em: <http://eur-lex.europa.eu/ legal-content/PT/TXT/?qid=1501748425875\&uri=CELEX:32012R1215> 
do reenvio prejudicial, que trataremos em seguida ${ }^{34}$.

\subsection{O reenvio prejudicial e a tramitação prejudicial urgente}

O reenvio prejudicial ${ }^{35}$ apresenta-se como um mecanismo jurisdicional de que os tribunais nacionais dos Estados-Membros podem dispor, quando se deparam com litígios que se inserem no âmbito de aplicação do direito da União, atuando, nesta sede, como tribunais funcionalmente europeus. Tem como escopo permitir aos juízes nacionais indagarem, junto do Tribunal de Justiça $a^{36}$, da interpretação ou da validade do direito da União que assume relevância para o caso sub judice - vide, a propósito, artigos $19^{\circ}$ do Tratado da União Europeia (TUE) e $267^{\circ}$ do TFUE.

Conforme foi veiculado pelo próprio Tribunal de Justiça, nas suas Recomendações sobre o reenvio prejudicial, este é "o mecanismo fundamental do direito da União Europeia, que tem por finalidade fornecer aos órgãos jurisdicionais dos Estados-membros o meio de assegurar uma interpretação e uma aplicação uniformes deste direito em toda a União" ${ }^{37}$. No entanto, entre os tribunais nacionais e o Tribunal

34 Tais derivações beberam influências na teoria da interconstitucionalidade aventada por Gomes Canotilho e demais estudiosos dos fenómenos “inter-". A propósito, e entre outros, CANOTILHO, José Joaquim Gomes. "Estado de direito e internormatividade". Em: SILVEIRA, Alessandra (Ed.). Direito da União Europeia e Transnacionalidade, Ação Jean Monnet (Information and Research Activities). Lisboa: Quid Juris, 2010, p. 171-185; CANOTILHO, José Joaquim Gomes. "Brancosos" e Interconstitucionalidade. Itinerários dos discursos sobre a historicidade constitucional. Coimbra: Almedina, 2006; RANGEL, Paulo Castro. O estado do Estado. Ensaios de política constitucional sobre justiça e democracia. Alfragide: Dom Quixote, 2009; MADURO, Miguel Poiares. A Constituição Plural. Constitucionalismo e União Europeia. Lisboa: Principia, 2006; MADURO, Miguel Poiares. "Three Claims of Constitutional Pluralism". Em: AVBELJ, Matej e KOMAREK, Jan (Eds.). Constitutional pluralism in the European Union and beyond. Oregon: Hart Publishing Oxford and Portland, 2012; SILVEIRA, Alessandra. "Intersubjectividade, interdemocraticidade, interconstitucionalidade, Filosofia Política e juridicidade europeia". Em: ROSAS, João Cardoso e MOURA, Vitor (Ed.). Pensar radicalmente a humanidade, Ensaios em homenagem ao Prof. Doutor Acílio da Silva Estanqueiro Rocha. Braga: Edições Humus, 2011, p. 9-27.

35 Para maiores desenvolvimentos, ABREU, Joana Covelo de. "Anotação ao Despacho do Tribunal de Justiça (10 Secção) de 16 de julho de 2015 - Processo no C-507/14". Anuário de Direito Internacional 2014/2015. Lisboa: Instituto Diplomático, Ministério dos Negócios Estrangeiros, 2016, p. 413- 426.

36 O Tratado de Lisboa introduziu algumas alterações na estrutura orgânica jurisdicional da União Europeia, na medida em que determinou, por conta do desaparecimento das Comunidades, que o Tribunal de Justiça das Comunidades Europeias - nomenclatura prévia ao Tratado de Lisboa - passasse a designar-se Tribunal de Justiça da União Europeia, sendo este composto pelo Tribunal de Justiça, pelo Tribunal Geral e pelos tribunais especializados, nos termos e para os efeitos do artigo $19^{\circ}, \mathrm{n}^{\circ} 1$ do TUE. Assim, estes tribunais configuram-se como tribunais organicamente europeus, na medida em que também os tribunais nacionais compõem a ordem jurisdicional europeia, na sua veste de tribunais funcionalmente europeus. Para maiores desenvolvimentos, SILVEIRA, Alessandra. Princípios de direito da União Europeia. Doutrina e Jurisprudência, 2a ed. Lisboa: Quid Iuris, p. 229 e seguintes.

37 TRIBUNAL DE JUSTIÇA DA UNIÃO EUROPEIA. Recomendações à atenção dos órgãos jurisdicionais nacionais, relativas à apresentação de processos prejudiciais. Luxemburgo: 06.11.2012, 2012/C 338/01, no 1, p. 1. [consulta 11/06/2017]. Disponível em: <http://eur-lex. 
de Justiça não existe nenhuma relação hierárquica ${ }^{38}$.

O reenvio prejudicial caracteriza-se por uma dinâmica objetiva enquanto "diálogo formal" 39 entre os tribunais dos Estados-Membros e o Tribunal de Justiça - e que observa um conjunto de regras próprias, nomeadamente as que resultam dos termos do artigo 267\% do TFUE: este artigo, aliás, demonstra-nos que este opera como "um instrumento de cooperação direta entre o Tribunal de Justiça e os órgãos jurisdicionais nacionais" 40 . Simultaneamente, podemos-lhe adivinhar uma dimensão subjetiva na medida em que se encontra "ao serviço da tutela jurisdicional efetiva" ${ }^{4}$. Afinal, apesar de não se encontrar na disposição direta dos particulares (porque o Tribunal de Justiça não funciona nem pretende funcionar como um tribunal de recurso e, portanto, os particulares não têm legitimidade ativa neste cerne), o reenvio pressupõe que o Tribunal de Justiça possa fornecer, ao tribunal nacional - que tem de acautelar diretamente os direitos das partes -, os dados necessários em sede de interpretação ou de validade do direito da União aplicável ao litígio, permitindo-lhe decidir e, bem assim, promover a justiça material e o enquadramento dos direitos conferidos pela ordem jurídica europeia. Afinal, é o juiz nacional que irá aplicar, ao caso concreto, a interpretação / a apreciação da validade do direito da União feita pelo Tribunal de Justiça na medida em que "não compete ao Tribunal [de Justiça] pronunciar-se sobre questões de facto suscitadas no âmbito do litígio no processo principal nem sobre eventuais divergências de opinião quanto à interpretação ou à aplicação das regras de direito nacional" ${ }^{42}$, embora o Tribunal de Justiça se esforce por dar uma resposta útil à boa solução do litígio em que emergiu a dúvida relativa ao direito da União.

O reenvio prejudicial pode, contudo, revelar-se indispensável em processos que revestem, intrínseca ou extrinsecamente, um caráter de urgência. Na realidade, "desde o dia 1 de março de 2008, o Tribunal de Justiça dispõe de um novo instrumento processual que lhe permite decidir questões prejudiciais relativas ao atualmente denominado espaço de liberdade, segurança e justiça (ELSJ)" "3. Tal tramitação permite-lhe

europa.eu/legal-content/PT/TXT/PDF/?uri=OJ:C:2012:338:FULL\&from=EN>

38 DASHWOOD, Alan; DOUGAN, Michael; RODGER, Barry; SPAVENTA, Eleanor; e WYATT, Derrick. European Union Law, 6a ed. Oxford: Hart Publishing, 2011, p. 209 a 210 e 216.

39 A propósito, TIMMERMANS, Christiaan. "Multilevel judicial co-operation". Em: CARDONNEL, Pascal; ROSAS, Allan; e WAHL, Nils (Eds.). Constitutionalising the EU judicial system: Essays in honour of Pernilla Lindh, Oxford: Hart Publishing, 2012, p. 16.

40 RODRIGUES, Maria Eugénia Martins de Nazaré. "Anotação ao artigo 267 do TFUE". Em: PORTO, Manuel Lopes e ANASTÁCIO, Gonçalo (Ed.). Tratado de Lisboa Anotado e Comentado. Coimbra: Almedina, 2012, p. 962-966, p. 963.

41 SILVEIRA, Alessandra. Princípios de direito da União Europeia. Op. cit., p. 233.

42 TRIBUNAL DE JUSTIÇA DA UNIÃO EUROPEIA. Recomendações à atenção dos órgãos jurisdicionais.... Op. cit., $\mathrm{n}^{\circ}$ 7, p. 2.

43 PATRÍCIO, Helena. "O mandado de detenção europeu na jurisprudência do Tribunal de Justiça”. UNIO - EU Law Journal 2014, no 0, 2014, p. 62-82, p. 73 [consulta 19/06/2017]. Disponível em: <http://www.unio.cedu.direito.uminho.pt/Uploads/UNIO\%200\%20-\%20 
decidir "dentro de prazos mais curtos do que os previstos em regra para o reenvio prejudicial, em conformidade com as exigências de celeridade que possam colocar-se nos domínios abrangidos"44.

Da leitura combinada do artigo $23^{\circ}-\mathrm{A}$ do Estatuto do Tribunal de Justiça $\mathrm{a}^{45}$ e dos artigos $107^{\circ}$ a $114^{\circ}$ do Regulamento de Processo do Tribunal de Justiça ${ }^{46}$, o reenvio prejudicial poderá observar uma tramitação prejudicial especial, do tipo urgente, sempre que as matérias objeto do reenvio prejudicial sejam relativas "ao espaço de liberdade, segurança e justiça" já que acarreta "condicionantes ainda mais significativas às pessoas envolvidas, uma vez que limita, designadamente, o número de partes autorizadas a apresentar observações escritas" e, "em casos de extrema urgência, [permite] omitir completamente a fase escrita do processo no Tribunal" 47 .

Para o efeito, "a aplicação desta tramitação só dever[á] ser pedida em circunstâncias em que seja absolutamente necessário que o Tribunal se pronuncie muito rapidamente sobre as questões submetidas pelo órgão jurisdicional de reenvio" 48 . Assim, o Tribunal de Justiça assevera que são vastas as matérias que se podem subsumir ao Espaço de Liberdade, Segurança e Justiça embora concretize algumas matérias onde é mais intuitivo o seu decretamento: "um órgão jurisdicional nacional poderá apresentar um pedido de tramitação prejudicial urgente, por exemplo, no caso [...] de uma pessoa detida ou privada de liberdade [...] ou no caso de um litígio relativo a poder paternal ou à guarda de crianças [... ${ }^{\prime 49}$.

Assim, a tramitação prejudicial urgente caracteriza-se por um encurtamento dos prazos para apresentação de alegações e de observações escritas - o prazo é fixado pelo Tribunal de Justiça que o comunica com a decisão da tramitação e com a data previsível da audiência. Tal tramitação deverá ser requerida pelo tribunal nacional: nos termos do disposto no artigo $107^{\circ}, \mathrm{n}^{\circ} 2$ do Regulamento de Processo do Tribunal de Justiça, este tem de expor as circunstâncias de direito e de facto comprovativas da urgência que justificam este tipo de tramitação. Nesta exposição, o tribunal nacional deverá, sempre que

\footnotetext{
Helena\%20Patricio_pt.pdf>

44 Ídem.

45 Dispõe o artigo $23 .^{\circ}$-A $1 .^{\circ}$ parágrafo do Estatuto do Tribunal de Justiça da União Europeia, na versão consolidada do Protocolo ( $\left.n^{\circ} 3\right)$, anexo aos Tratados: O Regulamento de Processo pode prever a tramitação acelerada de certos processos e a tramitação urgente dos pedidos de decisão prejudicial relativos ao espaço de liberdade, de segurança e de justiça".

46 UNIÃO EUROPEIA. Regulamento de Processo do Tribunal de Justiça, de 25 de setembro de 2012 (JO L 265 de 29 de setembro de 2012), alterado em 18 de junho de 2013 (JO L 173 de 26 de junho de 2013) e em 19 de julho de 2016 (JO L 217 de 12 de agosto de 2016) [consulta 11/06/2017]. Disponível em: <http://eur-lex.europa.eu/legal-content/PT/TXT/PDF/?uri=CELEX:32012Q0 929(01)\&from $=$ PT>

47 TRIBUNAL DE JUSTIÇA DA UNIÃO EUROPEIA. Recomendações à atenção dos órgãos jurisdicionais. Op. cit., no 39, p. 5.

48 Ibíd., n 39, $2^{\text {a }}$ parte, p. 5.

49 Ibíd., n 40, p. 5.
} 
possível, elencar os riscos em que se incorrerá se a questão prejudicial não for respondida com efetiva urgência. Pelo exposto, verificamos a cumulação de dois requisitos:

- de carácter material: o litígio tem de se subsumir a uma das matérias do Espaço de Liberdade, Segurança e Justiça (e não apenas às matérias elencadas no atual artigo $267.0^{\circ}, 4{ }^{\circ}$ parágrafo do TFUE ou àquelas que o Tribunal de Justiça avançou, na sua nota informativa ${ }^{50}$, como sendo mais usuais);

- de carácter casuístico: demonstração da urgência em obter a resposta à questão prejudicial.

$\mathrm{O}$ artigo $107^{\circ}, \mathrm{n}^{\circ} 2$, in fine do Regulamento de Processo veicula ainda que o juiz nacional, sendo-lhe possível, deverá indicar qual o sentido que lhe parece que as respostas do Tribunal de Justiça irão seguir.

Por sua vez, se o órgão jurisdicional de reenvio não tiver pedido a aplicação da tramitação urgente, o presidente do Tribunal poderá, excecionalmente, pedir à secção competente que examine se é necessário submeter o reenvio a tal tramitação quando, à primeira vista, tal se lhe afigurar necessário (artigo 107º, no 3 do Regulamento de Processo do Tribunal de Justiça).

A decisão de submeter um dado reenvio a tramitação urgente é tomada pela secção designada para o efeito, sob proposta do seu juiz-relator, depois de ouvido o Advogado-Geral (artigo 108 ${ }^{\circ}, \mathrm{n}^{\circ} 1$ do Regulamento de Processo), a qual é imediatamente notificada ao tribunal de reenvio, às partes, ao Estado-Membro, à Comissão e à Instituição (ou Instituições) que tiver adotado o ato objeto do reenvio (artigo $109^{\circ}, \mathrm{n}^{\circ} 2$ do Regulamento do Processo).

Por conta da necessidade de obter a decisão do Tribunal de Justiça em curto tempo, "apenas participam na fase escrita as partes no processo principal, o Estado-Membro ao qual pertence o órgão jurisdicional de reenvio, a Comissão e as outras Instituições se estiver em causa um dos seus atos; dado que estes dominam a língua do processo, a fase escrita pode ter início imediatamente, sem ser necessário esperar pela tradução do reenvio prejudicial em todas as línguas oficiais" 51 . Do mesmo modo, o Tribunal de Justiça conta com uma das suas secções para tramitar tais pedidos, a qual é especialmente determinada para o efeito.

$\mathrm{Na}$ sequência da decisão do Tribunal de Justiça a decretar a

50 A propósito, TRIBUNAL DE JUSTIÇA DA UNIÃO EUROPEIA. Nota informativa relativa à apresentação de pedidos de decisão prejudicial pelos órgãos jurisdicionais nacionais Complemento na sequência da entrada em vigor da tramitação urgente aplicável aos pedidos de decisão prejudicial relativos ao espaço de liberdade, de segurança e de justiça, no 7, p. 3 . Luxemburgo: 26/09/2008 [consulta 18/07/2017]. Disponível em: <https://curia.europa.eu/ jcms/upload/docs/application/pdf/2008-09/noteppu_2008-09-26_10-59-21_831.pdf>

51 MOTA DE CAMPOS, João; PEREIRA, António Pinto; e MOTA DE CAMPOS, João Luiz. O Direito Processual da União Europeia. Contencioso Comunitário, 2a ed. Lisboa: Fundação Calouste Gulbenkian, 2014, p. 476. 
tramitação prejudicial urgente verifica-se imediatamente a notificação da data previsível para a realização da audiência (artigo $109^{\circ}, \mathrm{n}^{\circ} 5$ do Regulamento de processo).

$\mathrm{O}$ artigo $111^{\circ}$ do Regulamento estabelece que, em casos de extrema urgência, a secção poderá decidir omitir a fase escrita do processo prejudicial.

Tendo em conta o regime jurídico inerente à decretação da tramitação urgente, há que atentar à realidade e aos ganhos temporais que a implementação desta tramitação especial acarretou. Neste contexto, o Tribunal de Justiça publicou, recentemente, o seu Relatório Anual de 2016, onde se refere que a duração média dos processos que aí tramitam ordinariamente é de 14,7 meses $^{52}$; no entanto, sempre que se tratam de reenvios prejudiciais especiais, nomeadamente que observam a tramitação prejudicial urgente, a média cifra-se em 2,7 meses ${ }^{53}$.

Ora, atentas as considerações vertidas quanto aos processos atinentes à cobrança de créditos no contexto da União, os considerandos iniciais dos Regulamentos que os instituem ovacionam a celeridade processual que os mesmos pressupõem. Acresce ainda que todas estas matérias se inserem no âmago do Espaço de Liberdade, Segurança e Justiça, podendo - e, na nossa perspetiva, devendo - os reenvios prejudiciais a eles atinentes observar esta tramitação urgente.

\subsection{A tramitação prejudicial urgente e a cobrança de créditos - relação simbiótica}

Conforme ficou claramente plasmado atrás, a tramitação prejudicial urgente, para ser decretada, pressupõe que o reenvio tenha por objeto a interpretação e / ou a aferição de validade de uma norma inserida no âmbito do Espaço de Liberdade, Segurança e Justiça. A este requisito material, aduzimos um requisito casuístico - o tribunal nacional (e, excecionalmente, o Presidente do Tribunal de Justiça, quando considere necessário) tem de demonstrar o carácter de urgência imanente ao processo dos autos em que a interpretação e / ou validade de uma disposição de direito da União se revela essencial.

Ora, como também tivemos oportunidade de asseverar, o procedimento de injunção e as ações de pequeno montante já se encontram em vigor, no ordenamento jurídico da União, há longos anos. No entanto, foram objeto de recente alteração legislativa, levada

\footnotetext{
52 Este período médio de duração é determinado por diversos fatores, sendo o mais preponderante a tradução de todos os documentos, requerimentos, observações, etc., apresentados no contexto de um reenvio prejudicial, na medida em que vigora a prerrogativa de os intervenientes processuais se poderem dirigir ao Tribunal de Justiça na sua língua mãe, desde que seja uma das línguas oficiais da União Europeia. Assim, as demandas de tradução são grandes, o que determina uma maior morosidade processual.

53 TRIBUNAL DE JUSTIÇA DA UNIÃO EUROPEIA. Relatório Anual 2016 - "Panorama do Ano". 2017, p. 28, [consulta 19/06/2017]. Disponível em: <https://curia.europa.eu/jcms/upload/ docs/application/pdf/2017-04/ti_pubpdf_qdaq17001ptn_pdfweb_20170424163218.pdf>
} 
a efeito através do mencionado Regulamento no 2015/2421, que será plenamente aplicável a partir do dia 14 de julho de 2017. Do mesmo modo, o arresto de contas bancárias é plenamente aplicável a partir de 18 de janeiro de 2017.

Assim, as facilidades inerentes ao Regulamento $\mathrm{n}^{\circ}$ 1896/2006 (relativo ao procedimento de injunção) e ao Regulamento no 861/2007 (relativo às ações de pequeno montante) encontram-se disponíveis há vários anos. No entanto, das pesquisas jurisprudenciais realizadas para este fim, verificámos que o Tribunal de Justiça nunca decretou a tramitação prejudicial urgente em nenhum processo de reenvio que tivesse por objeto a interpretação das disposições de um daqueles Regulamentos $^{54}$. Já ficou, contudo, bem demonstrado que quer o requisito material, quer o requisito casuístico se preenchem no âmbito da cobrança transfronteiriça de créditos - porque subsumível aos termos do disposto no artigo $81^{\circ}$ do TFUE, relativo à cooperação judiciária em matéria civil e, portanto, dentro do leque de matérias do Espaço de Liberdade, Segurança e Justiça, conforme este resulta do disposto no artigo $67^{\circ}$ do TFUE, nomeadamente o seu $\mathrm{n}^{\circ} 4$.

Afinal, quer o procedimento de injunção, quer as ações de pequeno montante criam um processado próprio no seio da União Europeia e, bem assim, afiguram-se como mecanismos tendentes a congregarem soluções jurídico-processuais acessíveis a todos aqueles que interagem economicamente no contexto europeu. Assim, quer num Regulamento, quer no outro, podemos encontrar, na teleologia vertida nos seus considerandos, expressões que os caracterizam por criarem processos céleres e simples, pelo que até o enquadramento abstrato do pressuposto casuístico está preenchido. Cabe depois ao juiz nacional um papel bem mais simplificado: poderá e deverá explicar a urgência associada à decisão, nomeadamente o risco que o requerente / autor corre se o processo demorar, como com a existência mais ou menos premente de uma de insolvência, de uma dispersão patrimonial na pendência da ação, etc. Mas trata-se de uma concretização, embora abstratamente a urgência já seja uma característica inerente aos próprios processos.

Do mesmo modo, o Regulamento relativo ao arresto de contas bancárias (Regulamento $n^{\circ} 655 / 2014$ ) cria um verdadeiro procedimento cautelar, o qual congrega carácter de urgência imanente (afinal, não é outra a definição de procedimento cautelar), podendo entender-se que aqui o preenchimento de ambos os requisitos é automático: trata-se de

54 A Autora conduziu uma pesquisa booleana no sítio da internet do Tribunal de Justiça (www.curia.europa.eu) através dos números dos Regulamentos referenciados e, bem assim, através da escolha da opção de consulta "apenas processos com tramitação prejudicial urgente". Desta confrontação, a Autora não encontrou um único exemplo de acórdão proferido ao abrigo desta modalidade de tramitação e, bem assim, pôde constatar que nenhum pedido de tramitação urgente foi também submetido ao Tribunal de Justiça por nenhum tribunal nacional que apresentou os pedidos de reenvio. 
um ato adotado no seio do Espaço de Liberdade, Segurança e Justiça e é, por natureza, um processo urgente que, como tal, demanda uma tramitação prejudicial consentânea com o seu cunho. $\mathrm{Na}$ realidade, este Regulamento pressupõe que a decisão de arresto seja tomada com especial celeridade ${ }^{55}$, o que não se compadece, em absoluto, com outra tramitação prejudicial que não seja a urgente.

Da análise jurisprudencial depreendemos que a tramitação prejudicial urgente é normalmente adotada para processos relacionados com família e as suas relações com os menores, quando se trate de um processo em que há uma pessoa detida ou presa ou, ainda, em matéria de vistos, asilo e imigração ${ }^{56}$. Assim, apesar de tais matérias serem das mais fraturantes em sede do Espaço de Liberdade Segurança e Justiça - e figurarem nos exemplos dados nas Recomendações do Tribunal de Justiça sobre o reenvio prejudicial e no seu Complemento - a realidade é que há tantas outras matérias que mereciam tal atenção. Este Espaço é muito mais amplo do que estas circunstâncias e onde, comprovada e teleologicamente, já se depreende que há situações de urgência na medida em que ou o carácter simplificado dos processos ou o baixo valor associado ao pedido ou o próprio carácter de providência cautelar ditam que a tramitação prejudicial urgente seja a única que deva ser cogitada.

No entanto, não podemos esperar que o Tribunal de Justiça, oficiosamente e de forma excecional, vá decretar esta forma de tramitação única e exclusivamente a seu próprio mote, sobretudo quando sabemos existir uma secção que se dedica ao seu processamento e não se quer votar o seu trabalho a uma maior lentidão.

55 A propósito, Regulamento (UE) n ${ }^{\circ}$ 655/2014, artigo $18^{\circ}$.

56 Sem pretensões de esgotamento do tema, podemos organizar, por temáticas, os acórdãos emanados tramitando como reenvios prejudiciais urgentes, a saber:

- Cooperação judiciária em matéria civil (execução das decisões em matéria matrimonial e em matéria de responsabilidade parental): acórdãos TRIBUNAL DE JUSTIÇA DA UNIÃO EUROPEIA Rinau, processo no C-195/08 PPU; Detiček, processo n ${ }^{\circ}$ C-403/09 PPU; Povse, processo $\mathrm{n}^{\circ} \mathrm{C}-211 / 10 \mathrm{PPU}$; $\mathrm{McB}$, processo $\mathrm{n}^{\circ} \mathrm{C}-400 / 10 \mathrm{PPU}$; Aguirre Zarraga, processo $\mathrm{n}^{\circ}$ C-491/10 PPU; Mercredi, processo ${ }^{\circ}$ C-497/10 PPU; Health Service Executive, processo $\mathrm{n}^{\circ}$ C-92/12 PPU; C., processo n ${ }^{\circ}$ C-376/14 PPU; Bradbrooke, processo n ${ }^{\circ}$ C-498/14 PPU; P., processo $\mathrm{n}^{\circ} \mathrm{C}-455 / 15 \mathrm{PPU}$; OL, processo $\mathrm{n}^{\circ} \mathrm{C}-111 / 17 \mathrm{PPU}$;

- Cooperação policial e judiciária em matéria penal: acórdãos TRIBUNAL DE JUSTIÇA DA UNIÃO EUROPEIA Santesteban Goicoechea, processo n C-296/08 PPU; Leymann e Pustovarov, processo ${ }^{\circ}$ C-388/08 PPU; Gataev e Gataeva, processo no C-105/10 PPU; West, processo $\mathrm{n}^{\circ}$ C-192/12 PPU; F., processso $\mathrm{n}^{\circ}$ C-168/13 PPU; Spasic, processo $\mathrm{n}^{\circ} \mathrm{C}-129 / 14 \mathrm{PPU}$; Lanigan, processo $\mathrm{n}^{\circ}$ C-237/15 PPU; A., processo n. C-463/15 PPU; Căldăraru, processo no C-659/15 PPU; Kovalkovas, processo no C-477/16 PPU; Özçelik, processo no C-453/16 PPU; Poltorak, processo $n^{\circ}$ C-452/16 PPU; Milev, processo no C-439/16 PPU; JZ, processo $\mathrm{n}^{\circ}$ C-294/16 PPU; Dworzecki, processo no C-108/16 PPU; e A., processo no $\mathrm{C}-463 / 15 \mathrm{PPU}$;

- Vistos, asilo, imigração: acórdão TRIBUNAL DE JUSTIÇA DA UNIÃO EUROPEIA Kadzoev, processo $\mathrm{n}^{\circ} \mathrm{C}-357 / 09$ PPU; El Dridi, processo $\mathrm{n}^{\circ} \mathrm{C}-61 / 11 \mathrm{PPU}$; Mohammad Imran, processo $\mathrm{n}^{\circ} \mathrm{C}-155 / 11$ PPU; Vo, processo $\mathrm{n}^{\circ} \mathrm{C}-83 / 12 \mathrm{PPU}$; Adil, processo $\mathrm{n}^{\circ} \mathrm{C}-278 / 12 \mathrm{PPU}$; G. e R., processo $\mathrm{n}^{\circ} \mathrm{C}-383 / 13$ PPU; Mahdi, processo $\mathrm{n}^{\circ} \mathrm{C}-146 / 14$ PPU; X e X, processo $\mathrm{n}^{\circ} \mathrm{C}-638 / 16$ PPU; N., processo ${ }^{\circ}$ C-601/15 PPU; e Mirza, processo n ${ }^{\circ}$ C-695/15 PPU. 


\section{CONCLUSÕES}

Os mecanismos de cobrança de créditos no contexto alargado da União Europeia - cujo ano de 2017 é sobejamente preponderante pois é no seu decurso que as novidades se começaram a aplicar - vieram adensar "as soluções jurídico-processuais que [a União] já oferecia, mais consentâneas com a realidade, permitindo às partes conhecer, mais cabalmente, o regime jurídico a que fica sujeito o processo que iniciam" ${ }^{\prime \prime}$. Na realidade, quer as alterações operadas em sede de ações de pequeno montante e de injunções europeias, quer o novo regime de arresto de contas se pautam pela sedimentação de processos-tipo, de caráter alternativo às soluções jurídico-processuais internas, mas que determinam como a tramitação se irá observar, no contexto da União, desde que o requerimento inicial é apresentado até à decisão final. Assim, "as devoluções para as soluções jurídico-processuais dos EstadosMembros se oper[a]m menos vezes e, deste modo, a previsibilidade de como o processo se desenrolará é maior" 58 .

A sedimentação de formas de tramitação puramente europeias, que terão de ser observadas e implementadas pelos tribunais nacionais, numa perspetiva de proximidade aos elementos determinantes do litígio, acaba por colocar as matérias relativas à cooperação judiciária em matéria civil na ordem do dia. Aliás, na senda da criação destes mecanismos, há mesmo autores que se referem à emergência de um "processo civil europeu" 59 , nomenclatura que, apesar de indiciadora da maior integração sentida, nós rejeitamos.

Na realidade, a utilização de expressões demasiadamente ataviadas à estrutura processual nacional apenas irá comprometer o processo de integração que se está a desenhar; por sua vez, consideramos que o vocábulo "cooperação" que encontramos na temática onde a cobrança de créditos se encerra está demasiadamente conexionado a um período histórico da União em que a cooperação entre Estados-Membros era o fluxo procurado e onde as decisões eram tomadas observando o método intergovernamental. Ora, atualmente, o estádio de interação entre os ordenamentos jurídicos dos Estados-Membros e da União Europeia assumiu proporções de marcada importância pelo que, criando-se mecanismos próprios de tramitação de demandas creditícias, em contexto europeu, seria mais consentâneo - sem criar fricções ou temores

57 ABREU, Joana Covelo de. "O impacto do Regulamento no 2015/2421 no funcionamento das ações de pequeno montante - compreensões quanto à justiça eletrónica europeia”. Op. cit., p. 16 (provisório).

58 Ídem.

59 Entre outros, BIAVATI, Paolo. Op. cit., p. 565; TARZIA, Giuseppe. "L’ordine europeo del processo civile". Rivista de diritto processualle, 2001, n 4, p. 902; e CANNIZZARO, Enzo. "Sui rapporti tra sistemi processuali nazionali e diritto dell'Unione Europea”. Il Diritto dell'Unione Europea, 2008, n 1, p. 447. 
de atentado às soberanias nacionais - falar já em integração judiciária em matéria civil. Afinal, as realidades aqui estudadas fornecem-nos "o mote para nos deslocarmos da nomenclatura intergovernamental de "cooperação" e da denominação inerente ao ideário estadual de "direito processual civil europeu" 60 .

Aqui chegados, cabe, assim, afirmar que, face às novidades implementadas em sede de cobrança de créditos na União Europeia - que conhece, no ano de 2017, um ano de concretização e de melhoramento -, este texto tem de se pautar por dois apelos dogmático-conclusivos:

- um apelo à consciência: num contexto em que o reenvio prejudicial permite o diálogo direto dos tribunais nacionais com o Tribunal de Justiça, os operadores judiciários têm, de forma mais premente, de enraizar a necessidade de apresentarem mais e melhores reenvios prejudiciais, absolutamente fundamentais em regimes que se pautam por novidades relativas ao seu funcionamento. Afinal, apesar de "a interação reflexiva entre ordens jurisdicionais que convivem no mesmo espaço jurídico não se esgota[r] no exercício presente de um reenvio prejudicial"'61, a realidade é que este é a forma mais adequada para o juiz nacional deslindar as suas dúvidas quando tenha de aplicar o direito da União, especialmente quando se trata de regimes com novos contornos; $\mathrm{e}$

- um apelo à necessidade: já que é imprescindível despertá-los para o facto de existir uma tramitação prejudicial urgente que se aplica também aos domínios da cobrança de créditos uma vez que estes se encontram ao serviço da criação e implementação de um Espaço de Liberdade, Segurança e Justiça.

Revela-se, assim, muito problemático intuir porque não foi ainda decretada esta tramitação em reenvios prejudiciais onde dúvidas sobre a interpretação e / ou validade de termos de atos normativos relativos à cobrança de créditos surgem. Assim, num exercício preventivo, cabe à academia contactar os operadores judiciários e consciencializá-los que este salto qualitativo é preciso e que têm de começar, a par e passo da estruturação das razões que justificam os seus reenvios, a equacionar quando podem efetivamente requerer a sua tramitação urgente em matérias atinentes à cobrança de créditos, já que as mesmas passaram

60 ABREU, Joana Covelo de. "O impacto do Regulamento no 2015/2421 no funcionamento das ações de pequeno montante - compreensões quanto à justiça eletrónica europeia”. Op. cit., p. 17 (provisório).

61 ABREU, Joana Covelo de. “O acórdão do Tribunal Constitucional português no 591/2016 em matéria de concessão de apoio judiciário a pessoas coletivas com fins lucrativos e a jurisprudência do Tribunal de Justiça - reflexões prospetivas à luz da interjurisdicionalidade”. Em: SILVEIRA, Alessandra (Ed.). UNIO - e-book, Volume II, Workshops CEDU. Braga: Centro de Estudos em Direito da União Europeia, 2017, no prelo, p. 12 (provisório). 
a assumir-se como prioridades da justiça europeia e como um meio de resposta às demandas de tutela jurisdicional efetiva.

Concretizando: as partes, nestes contextos, querem ver os créditos de que são detentoras pagos e a tutela efetiva dos seus direitos manifesta-se se tal cobrança for bem sucedida, for célere e parcamente dispendiosa, podendo o devedor contraditar, em prazo razoável, o que lhe é imputado. Para o efeito, não nos podemos deparar com um processo demorado: ora, sendo um processo tramitado à luz do direito da União, o reenvio prejudicial pode surgir como uma necessidade e, neste caso, só a tramitação prejudicial urgente poderá evitar delongas excessivas nos processos.

Não pode o tempo inerente à emanação de uma decisão de reenvio votar à inutilidade mecanismos que estão também ao serviço do processo de integração.

\section{REFERÊNCIAS BIBLIOGRÁFICAS}

ABREU, Joana Covelo de. "A tutela jurisdicional efetiva no âmbito da cooperação judiciária em matéria civil e a jurisprudência do Tribunal de Justiça da União Europeia: a cláusula de ordem pública e a revelia absoluta como causas de recusa de reconhecimento e de execucão de decisões no contexto da União" [online]. UNIO - EU Law Journal 2014, $\mathrm{n}^{\circ} 0.2014$, p. 147-161 [consulta 09/06/2017]. Disponível em: $<\mathrm{http}: / /$ www.unio.cedu.direito.uminho.pt/Uploads/UNIO\%20PT/UNIO\%20 0\%20-\%20Joana\%20Abreu_pt.pdf>

ABREU, Joana Covelo de. "Anotação ao Despacho do Tribunal de Justiça (10 Secção) de 16 de julho de 2015 - Processo no C-507/14". Anuário de Direito Internacional 2014/2015. Lisboa: Instituto Diplomático, Ministério dos Negócios Estrangeiros, 2016, p. 413- 426.

ABREU, Joana Covelo de. "O acórdão do Tribunal Constitucional português no 591/2016 em matéria de concessão de apoio judiciário a pessoas coletivas com fins lucrativos e a jurisprudência do Tribunal de Justiça - reflexões prospetivas à luz da interjurisdicionalidade". Em: SILVEIRA, Alessandra (Ed.). UNIO - e-book, Volume II, Workshops $C E D U$. Braga: Centro de Estudos em Direito da União Europeia, 2017.

ABREU, Joana Covelo de. "O procedimento europeu de injunção de pagamento: solução simplificada de cobrança de créditos transfronteiriços?". Em: ROCHA, Joaquim Freitas dả (Ed.). Anuário Publicista da Escola de Direito da Universidade do Minho (e-book) [online]. Braga: Departamento de Ciências Jurídicas Públicas, Escola de Direito da Universidade do Minho, 2014. tomo 2, p. 77-91, p. 77 [consulta 09/06/2017]. Disponível em: <https://issuu.com/eduminho/ docs/final_anu_rio_2013_etica_e_direito>

ABREU, Joana Covelo de. “O Regulamento n. ${ }^{\circ}$ 655/2014 que estabelece um procedimento de decisão europeia de arresto de contas: direitos à ação e de defesa em tensão reflexiva no contexto de uma integração judiciária em matéria civil - uma precoce antevisão". Em: SILVEIRA, 
Alessandra (Ed.). UNIO - e-book, Vol. I, Workshops CEDU 2016 [online]. Braga: Centro de Estudos em Direito da União Europeia, 2017, p. 253276, p. 254 [consulta 19/06/2017]. Disponível em: <http://www.unio.cedu. direito.uminho.pt/Uploads/E-book\%20-\%20Vol.\%201\%20-\%202016.pdf>

ABREU, Joana Covelo de. "O impacto do Regulamento n 2015/2421 no funcionamento das ações de pequeno montante - compreensões quanto à justiça eletrónica europeia. Em: FONSECA, Isabel; FROUFE, Pedro Madeira; e ROCHA, Joaquim Freitas da (Ed.). Livro em Homenagem ao Professor Doutor Cândido Oliveira, Braga: 2017.

BIAVATI, Paolo. "Lavenir du droit judiciaire privé d’origine européenne. De l'harmonisation des règles à l'harmonisation des effets". RTDeur Revue trimestrielle de droit européen. 2010, vol 46, nº 3, p. 563-575.

CANNIZZARO, Enzo. "Sui rapporti tra sistemi processuali nazionali e diritto dell'Unione Europea”. Il Diritto dell'Unione Europea, 2008, nº 1, p. 447-459.

CANOTILHO, José Joaquim Gomes. "Brancosos" e Interconstitucionalidade. Itinerários dos discursos sobre a historicidade constitucional. Coimbra: Almedina, 2006.

CANOTILHO, José Joaquim Gomes. "Estado de direito e internormatividade". Em: SILVEIRA, Alessandra (Ed.). Direito da União Europeia e Transnacionalidade, Ação Jean Monnet (Information and Research Activities). Lisboa: Quid Juris, 2010, p. 171-185.

COMISSÃO EUROPEIA. EU Citizenship Report 2013, EU citizens: your rights, your future. Bruxelas: 08.05.2013, COM(2013) 269 final, p. 15 [consulta 10/6/2017]. Disponível em: <http://ec.europa.eu/justice/ citizen/files/com_2013_269_en.pdf>

COMISSÃO EUROPEIA. Proposta de Regulamento do Parlamento Europeu e do Conselho, que altera o Regulamento (CE) no 861/2007, do Parlamento Europeu e do Conselho, de 11 de julho de 2007. Disponível em: <http://eur-lex.europa.eu/legal-content/PT/ TXT/?uri=CELEX\%3A32007R0861>

COMISSÃO EUROPEIA. Proposta de Regulamento do Parlamento Europeu e do Conselho, que altera o Regulamento (CE) no 1896/2006, do Parlamento Europeu e do Conselho, de 12 de dezembro de 2006, que cria um procedimento europeu de injunção de pagamento. Bruxelas: 19.11.2013, COM (2013) 794 final, 2013/0403 (COD) [consulta 10/06/2017]. Disponivel em: <http://ec.europa.eu/transparency/regdoc/rep/1/2013/ PT/1-2013-794-PT-F1-1.Pdf>

DASHWOOD, Alan; DOUGAN, Michael; RODGER, Barry; SPAVENTA, Eleanor; e WYATT, Derrick. European Union Law. $6^{\mathrm{a}}$ ed. Oxford: Hart Publishing, 2011.

MADURO, Miguel Poiares. “Three Claims of Constitutional Pluralism”. Em: AVBELJ, Matej eKOMAREK, Jan (Eds.). Constitutional pluralism in the European Union and beyond. Oregon: Hart Publishing Oxford and Portland, 2012.

MARINHO, Carlos M.G. de Melo. A cobrança de créditos na Europa. 
Os processos europeus de injunção e pequenas causas. Lisboa: Quid Juris, 2012.

MOTA DE CAMPOS, João; PEREIRA, António Pinto; e MOTA DE CAMPOS, João Luiz. O Direito Processual da União Europeia. Contencioso Comunitário, $2^{\text {a }}$ ed. Lisboa: Fundação Calouste Gulbenkian, 2014, p. 476.

NASCIMBENE, Bruno. "Le traite de Lisbonne et l'espace judiciaire européen: le principe de confiance réciproque et de reconnaissance mutuelle". Revue des Affaires Européennes - Law \& European Affairs. 2012, p. 787-791.

PARLAMENTO EUROPEU E CONSELHO. Regulamento (CE) $\mathrm{n}^{\circ}$ $1896 / 2006$, de 12 de dezembro de 2006 , que cria um procedimento europeu de injunção de pagamento [consulta 09/06/2017]. Disponível em: <http://eur-lex.europa.eu/legal-content/PT/TXT/?qid=150174752 6470\&uri=CELEX:32006R1896>

PARLAMENTO EUROPEU E CONSELHO. Regulamento (CE) $n^{\circ}$ 861/2007, de 11 de julho de 2007, que estabelece um processo europeu para ações de pequeno montante [consulta 09/06/2017). Disponível em: $<$ http://eur-lex.europa.eu/legal-content/PT/TXT/?qid=1501747671600 \&uri=CELEX:32007R0861>

PARLAMENTO EUROPEU E CONSELHO. Regulamento (UE) $n^{o}$ 2015/2421, de 16 de dezembro de 2015, que altera o Regulamento (CE) $n^{\circ}$ 861/2007 que estabelece um processo europeu para ações de pequeno montante e o Regulamento (CE) no 1896/2006 que cria um procedimento europeu de injunção de pagamento [consulta 10/6/2017]. Disponível em: $<$ http://eur-lex.europa.eu/legal-content/PT/TXT/?qid=1501748132862 \&uri=CELEX:32015R2421>

PARLAMENTO EUROPEU E CONSELHO. Regulamento (UE) $n^{\circ}$ 655/2014, de 15 de maio de 2014, que estabelece um procedimento de decisão europeia de arresto de contas para facilitar a cobrança transfronteiriça de créditos em matéria civil e comercial [consulta 10/06/2017]. Disponível em: <http://eur-lex.europa.eu/legal-content/PT/TXT/?qid=150174828 5202\&uri=CELEX:32014R0655>

PATRÍCIO, Helena. "O mandado de detenção europeu na jurisprudência do Tribunal de Justiça". UNIO - EU Law Journal 2014, no 0, 2014, p. 62-82, p. 73 [consulta 19/06/2017]. Disponível em: <http://www.unio.cedu.direito. uminho.pt/Uploads/UNIO\%200\%20-\%20Helena\%20Patricio_pt.pdf>

PIÇARRA, Nuno. "As incidências do direito da União Europeia sobre a organização e o exercício da função jurisdicional dos EstadosMembros". Revista da Faculdade de Direito da Universidade do Porto, 2010, vol 8, p. 209-226.

RANGEL, Paulo Castro. O estado do Estado. Ensaios de política constitucional sobre justiça e democracia. Alfragide: Dom Quixote, 2009; MADURO, Miguel Poiares. A Constituição Plural. Constitucionalismo e União Europeia. Lisboa: Principia, 2006. 
RODRIGUES, Maria Eugénia Martins de Nazaré. “Anotação ao artigo $267^{\circ}$ do TFUE". Em: PORTO, Manuel Lopes e ANASTÁCIO, Gonçalo (Ed.). Tratado de Lisboa Anotado e Comentado. Coimbra: Almedina, 2012, p. 962-966.

ROSAS, João Cardoso e MOURA, Vitor (Ed.). Pensar radicalmente a humanidade, Ensaios em homenagem ao Prof. Doutor Acílio da Silva Estanqueiro Rocha. Braga: Edições Humus, 2011, p. 9-27.

SILVEIRA, Alessandra. Princípios de direito da União Europeia. Doutrina e Jurisprudência, 2a ed. Lisboa: Quid Iuris, s.f.

TARZIA, Giuseppe. "Lordine europeo del processo civile". Rivista de diritto processualle. 2001, $\mathrm{n}^{\circ} 4$, p. 902-937.

TIMMERMANS, Christiaan. "Multilevel judicial co-operation". Em: CARDONNEL, Pascal; ROSAS, Allan; e WAHL, Nils (Eds.). Constitutionalising the EU judicial system: Essays in honour of Pernilla Lindh, Oxford: Hart Publishing, 2012, p. 15-23.

TRIBUNAL DE JUSTIÇA DA UNIÃO EUROPEIA. Nota informativa relativa à apresentação de pedidos de decisão prejudicial pelos órgãos jurisdicionais nacionais - Complemento na sequência da entrada em vigor da tramitação urgente aplicável aos pedidos de decisão prejudicial relativos ao espaço de liberdade, de segurança e de justiça, no 7, p. 3. Luxemburgo: 26/09/2008 [consulta 18/07/2017]. Disponível em: $<$ https://curia.europa.eu/jcms/upload/docs/application/pdf/2008-09/ noteppu_2008-09-26_10-59-21_831.pdf>

TRIBUNAL DE JUSTIÇA DA UNIÃO EUROPEIA. Recomendações à atenção dos órgãos juriśdicionais nacionais, relativas à apresentação de processos prejudiciais. Luxemburgo: 06.11.2012, 2012/C 338/01, no 1, p. 1. [consulta 11/06/2017]. Disponível em: <http://eur-lex.europa.eu/ legal-content/PT/TXT/PDF/?uri=OJ:C:2012:338:FULL\&from=EN>

TRIBUNAL DE JUSTIÇA DA UNIÃO EUROPEIA. Relatório Anual 2016 - "Panorama do Año". 2017 [consulta 19/06/2017]. Disponível em: $<$ https://curia.europa.eu/jcms/upload/docs/application/pdf/2017-04/ ti_pubpdf_qdaq17001ptn_pdfweb_20170424163218.pdf $>$

UNIÃO EUROPEIA. Regulamento de Processo do Tribunal de Justiça, de 25 de setembro de 2012 (JO L 265 de 29 de setembro de 2012), alterado em 18 de junho de 2013 (JO L 173 de 26 de junho de 2013) e em 19 de julho de 2016 (JO L 217 de 12 de agosto de 2016) [consulta 11/06/2017]. Disponível em: <http://eur-lex.europa.eu/legal-content/PT/TXT/PDF/ ?uri=CELEX:32012Q0929(01)\&from=PT>

\section{RESUMO BIOGRÁFICO}

Joana Covelo Abreu é Doutora, Mestre e Licenciada em Direito pela Escola de Direito da Universidade do Minho, Portugal. Membro do CEDU, Centro de Estudos em Direito da Universidade do Minho. Investigadora Principal Convidada no Parlamento Europeu, Bruxelas (2014). Advogada. Professora da Escola de Direito da Universidade do Minho. 